\title{
GERENCIAMENTO DE STAKEHOLDERS NA GESTÃO DE PROJETOS: REVISANDO A
}

\author{
PUBLICAÇÃO CIENTÍFICA
}

\author{
Luana Ferreira dos Santos ${ }^{1}$ \\ Washington José de Sousa² \\ Recebido em: 10 dez. 2019 \\ Aceito em: 4 mar. 2020
}

\begin{abstract}
Como citar este artigo: SANTOS, L.; SOUSA, W. GERENCIAMENTO DE STAKEHOLDERS NA GESTÃO DE PROJETOS: REVISANDO A PUBLICAÇÃO CIENTÍFICA. Revista Visão: Gestão

Organizacional, v.9, n.1, p.71-83, 2020. DOI: https://doi.org/10.33362/visao.v9i1.2159
\end{abstract}

Resumo: Este artigo tem como objetivo realizar uma revisão sistemática da literatura a respeito dos estudos de gerenciamento de stakeholders no âmbito dos artigos indexados no repositório do Portal de Periódicos da Coordenação de Aperfeiçoamento de Pessoal de Nível Superior (Capes). Para tal, foi utilizado o protocolo Principais Itens para Relatar Revisões sistemáticas e Meta-análises (Prisma), para a seleção de sete artigos, que foram contemplados na análise. Os resultados revelam aspectos das pesquisas que podem ser comparados aos quatro processos integrantes da área do conhecimento "partes interessadas", do Project Management Body of Knowledge (PMBOK), criado pelo Project Management Institute (PMI, 2013): i) identificação, ii) planejamento do gerenciamento, iii) gerenciamento do engajamento e iv) controle do engajamento. Foi possível verificar também, por meio dos trabalhos selecionados, elementos associados aos stakeholders contemplados pelas pesquisas, como a análise dos stakeholders em projetos de Tecnologia da Informação, os critérios de sucesso em projetos considerando a interferência dos stakeholders, as facilidades e dificuldades na gestão dos stakeholders, o desenvolvimento de um modelo conceitual abordando o gerenciamento dos stakeholders e a utilização de tipologias para classificá-los. Pode-se considerar a restrição ao banco de artigos do repositório do Portal de Periódicos da Capes como limitação do trabalho, o que deixa espaço para sugestão de pesquisas futuras, considerando outros repositórios para a realização de revisões sistemáticas referentes à temática do gerenciamento dos stakeholders na gestão de projetos.

Palavras-Chave: Stakeholders. Gestão de projetos. Project Management Body of Knowledge (PMBOK). Project Management Institute (PMI). Revisão sistemática de literatura.

STAKEHOLDER MANAGEMENT IN PROJECT MANAGEMENT: REVIEWING THE SCIENTIFIC PUBLICATION

\footnotetext{
1 Doutoranda em Administração pela Universidade Federal do Rio Grande do Norte (UFRN). Mestra em Administração e Gestora do Agronegócio pela Universidade Federal de Viçosa (UFV). Administradora pela Faculdade Estácio de Sá. E-mail: luana.f.s.adm@gmail.com.

2 Professor Titular do Departamento de Administração Pública e Gestão Social (DAPGS) da Universidade Federal do Rio Grande do Norte (UFRN). Doutor em Educação pela Universidade Federal do Ceará, mestre e graduado em Administração pela UFRN. E-mail: wsufrn@gmail.com.
} 
Abstract: This article aims to conduct a systematic literature review on stakeholder management studies within the indexed articles in the repository of the Coordination for the Improvement of Higher Education Personnel (Capes) Journal Portal. For this, was used the protocol Main Items to Report Systematic Reviews and Meta-analyzes (Prisma), for the selection of seven articles, which were included in the analysis. The findings reveal aspects of research that can be compared to the four stakeholder knowledge processes of the Project Management Body of Knowledge (PMBOK), created by the Project Management Institute (PMI, 2013): i) identification, ii) management planning, iii) engagement management and iv) engagement control. It was also possible to verify, through the selected works, elements associated with the stakeholders contemplated by the research, such as the analysis of stakeholders in Information Technology projects, the criteria of success in projects considering the interference of the stakeholders, the ease and difficulties in managing the stakeholders, the development of a conceptual model addressing stakeholder management and the use of typologies to classify them. The restriction to the article database of the Capes Journal Portal repository may be considered as a limitation of the work, which leaves room for suggestion of future research, considering other repositories to conduct systematic reviews on the topic of stakeholder management in the project management.

Keywords: Stakeholders. Project Management. Project Management Body of Knowledge (PMBOK). Project Management Institute (PMI). Systematic Literature Review.

\section{INTRODUÇÃO}

O gerenciamento dos stakeholders é um tema inserido no âmbito da gestão de projetos, sendo assim faz-se relevante conceituar projetos e stakeholders. O Project Management Institute (PMI, 2013) define projeto como um esforço temporário realizado para criar um produto, serviço ou resultado único, assim, a natureza temporária dos projetos indica que eles têm início e término definidos. Freeman (1984) define stakeholders como um grupo de pessoas que desempenham um papel vital no sucesso do negócio da empresa.

De acordo com Weible (2006), a definição do conceito de stakeholders está na resposta a um conjunto de perguntas: Quem são as partes interessadas para incluir na análise? Quais são os interesses e crenças dos interessados? Quem controla recursos críticos? Com quem as partes interessadas formam coalizões? Quais estratégias e locais os interessados usam para alcançar seus objetivos?

Freeman (1984) lista uma série de categorias de stakeholders, como governo, comunidade, funcionários, fornecedores, clientes, etc. Mesmo sendo apresentado e disseminado pela obra de Freeman (1984), o crescimento do debate acerca dos stakeholders em gestão de projetos no universo acadêmico ocorreu a partir da década de 2000, especialmente em 2013, com a incorporação da área do conhecimento denominada "partes interessadas" na quinta edição do Project Management Body of Knowledge (PMBOK), em 2013.

O PMBOK é um guia do PMI, reconhecido mundialmente na orientação do 
gerenciamento de projetos, estabelecendo normas, métodos, processos e práticas que evoluíram por meio de boas práticas utilizadas por profissionais que contribuíram para o seu desenvolvimento (PMI, 2013). A incorporação das partes interessadas no PMBOK é justificada pelo PMI (2013) pelo papel que os stakeholders desempenham no gerenciamento de projetos, visto que eles podem afetar ou ser afetados por uma decisão, atividade ou resultado de um processo, podendo estar envolvidos positiva ou negativamente com o projeto e exercer influência sobre o todo ou parte de sua execução.

De acordo com o PMBOK (PMI, 2013), uma boa governança de projeto implica no exercício de liderança pelo gerente de projeto por meio do alinhamento do projeto com as necessidades ou objetivos das partes interessadas. As partes interessadas incluem patrocinadores (pessoa ou grupo responsável por fornecer recursos e suporte para o projeto), clientes e usuários (pessoas ou organizações que aprovam e gerenciam o produto ou serviço resultante do projeto), vendedores (pessoas ou grupos externos que fornecem insumos para o projeto), parceiros de negócios (organizações externas que possuem relação especial com a empresa), grupos organizacionais (partes internas afetadas pelo projeto), gerentes funcionais (partes que exercem a função gerencial na estrutura organizacional) e outras partes interessadas (órgãos públicos, consultores, entidades diversas etc.). O PMI (2013) aborda partes interessadas como sinônimo de stakeholders.

Para Gao e Zang (2006), as relações entre os stakeholders devem ser compreendidas como um complexo jogo de relações de mudanças ambíguas e contestadas entre/dentro de diversos stakeholders e organizações. Ou seja, compreender como as relações entre os stakeholders têm sido abordada nas pesquisas científicas é relevante para a análise de como essas relações se manifestam em diferentes tipos de organizações.

A análise dos stakeholders tem sido empregada em diferentes pesquisas. Conforme Gupta (1995), a análise de stakeholders identifica e especifica as partes interessadas e seus interesses, domínio e especificidade; identifica e descreve as relações de poder entre as partes interessadas e a empresa, e entre as partes interessadas; e incorpora os conceitos de ação e tempo. Já Schmeer (1999) entende que a análise de stakeholders como um processo de coleta e análise sistemática de informações qualitativas para determinar quais os interesses que devem ser levados em consideração ao desenvolver e/ou implementar uma política ou programa.

Segundo Gomes e Gomes (2007), a teoria dos stakeholders é uma abordagem viável para compreender o tipo de influências que uma organização recebe do seu ambiente, pois o conceito de stakeholder assume uma natureza bilateral das relações entre uma organização e seus stakeholders com base na capacidade da organização de exercer influência sobre eles e a probabilidade de sofrer influências deles.

Mushove e Vogel (2005) definem a análise de stakeholders como uma gama de 
ferramentas ou uma abordagem para a compreensão de um sistema, identificando os principais atores ou partes interessadas com base em seus atributos, inter-relações e avaliação de seus respectivos interesses relacionados ao sistema, emissão ou recurso. Neste trabalho, a análise dos stakeholders está relacionada ao gerenciamento destes, sendo definido por Freeman, Harrison e Wicks (2007, p. 6) "uma ideia multifacetada que nos permite ver que existem muitas maneiras de gerenciar com sucesso um negócio". O PMI (2013) destaca que a área gerenciamento dos stakeholders do PMBOK é composta por quatro processos: i) identificação, ii) planejamento, iii) gerenciamento do engajamento e iv) controle do nível de engajamento das partes interessadas.

Especificamente na área de gestão de projetos, dentre outros aspectos, o gerenciamento dos stakeholders também está associado à categorização dos stakeholders mais influentes (MARTINS, SILVA; SANTOS, 2013); à gestão diferenciada dos stakeholders (DUARTE, BIANCOLINO; KNIESS, 2013; DIAS, JEUNON, DUARTE, 2016) e à gestão de stakeholders na gestão de projetos de Tecnologia da Informação (TI) (LOPES; MAÑAS, 2013).

Sendo assim, esta pesquisa se orienta pelo seguinte questionamento: como o gerenciamento dos stakeholders tem sido estudado no âmbito das pesquisas científicas? Como exercício de resposta a tal questão, o trabalho tem como objetivo realizar uma revisão sistemática da literatura a respeito dos estudos de gerenciamento de stakeholders no âmbito dos artigos indexados no repositório do Portal de Periódicos da Coordenação de Aperfeiçoamento de Pessoal de Nível Superior (Capes).

A relevância desta pesquisa consiste em contribuir para o desenvolvimento da área por meio da análise do estado da arte das pesquisas que consideram o gerenciamento dos stakeholders no âmbito da gestão de projetos. A relevância também reside na importância dos stakeholders, visto que estes podem tanto afetar quanto serem afetados pelos projetos da organização, desempenhando um papel fundamental neste aspecto.

Franco et al. (2016) realizaram um estudo bibliométrico acerca da literatura dos stakeholders no gerenciamento de projetos, com o intuito de identificar o panorama da produção científica no período de 1991 até 2014. Este trabalho se diferencia da pesquisa em questão, pelo período de análise (2013 a 2019), e, pela abordagem empregada, visto que esta análise é realizada à luz dos aspectos que configuram a área "partes interessadas" do PMBOK (PMI, 2013).

\section{DESENVOLVIMENTO}

A construção desta revisão sistemática deu-se com o aparato do protocolo Principais Itens para Relatar Revisões sistemáticas e Meta-análises (Prisma), que consiste em um checklist com 27 itens e um fluxograma de quatro etapas que abordam a descrição dos itens que devem 
ser incluídos em uma revisão sistemática, sendo estas etapas: identificação, seleção, elegibilidade e inclusão (MOHER et al., 2015). A elaboração do estado da arte das pesquisas a respeito do gerenciamento dos stakeholders tomou como referência artigos da biblioteca eletrônica do Portal de Periódicos da Capes.

Os artigos foram coletados no site do referido Portal. As buscas pelos artigos foram realizadas da seguinte forma: no campo título foi colocado os descritores "stakeholders" e "partes interessadas", no período de publicação foi selecionado o campo "01 de janeiro de 2013" a "01 de setembro de 2019". O ano de 2013 se justifica por ter sido o ano no qual a área "partes interessadas" foi incorporada no PMBOK (2013), e, a outra data, respectivamente, a data na qual as buscas foram realizadas.

Como tipos de documentos, foram selecionados apenas "artigos", como idioma selecionou-se "português". Foi possível perceber que nem todos os trabalhos analisaram os stakeholders na perspectiva da gestão de projetos, sendo assim, aplicou-se também o filtro "projetos" no campo "resumo", retornando sete artigos na busca, que foram selecionados para análise. A Figura 1 relata o processo de escolha dos artigos, conforme os critérios do protocolo Prisma (identificação, seleção, elegibilidade e inclusão).

Figura 1: Etapas para a escolha dos artigos

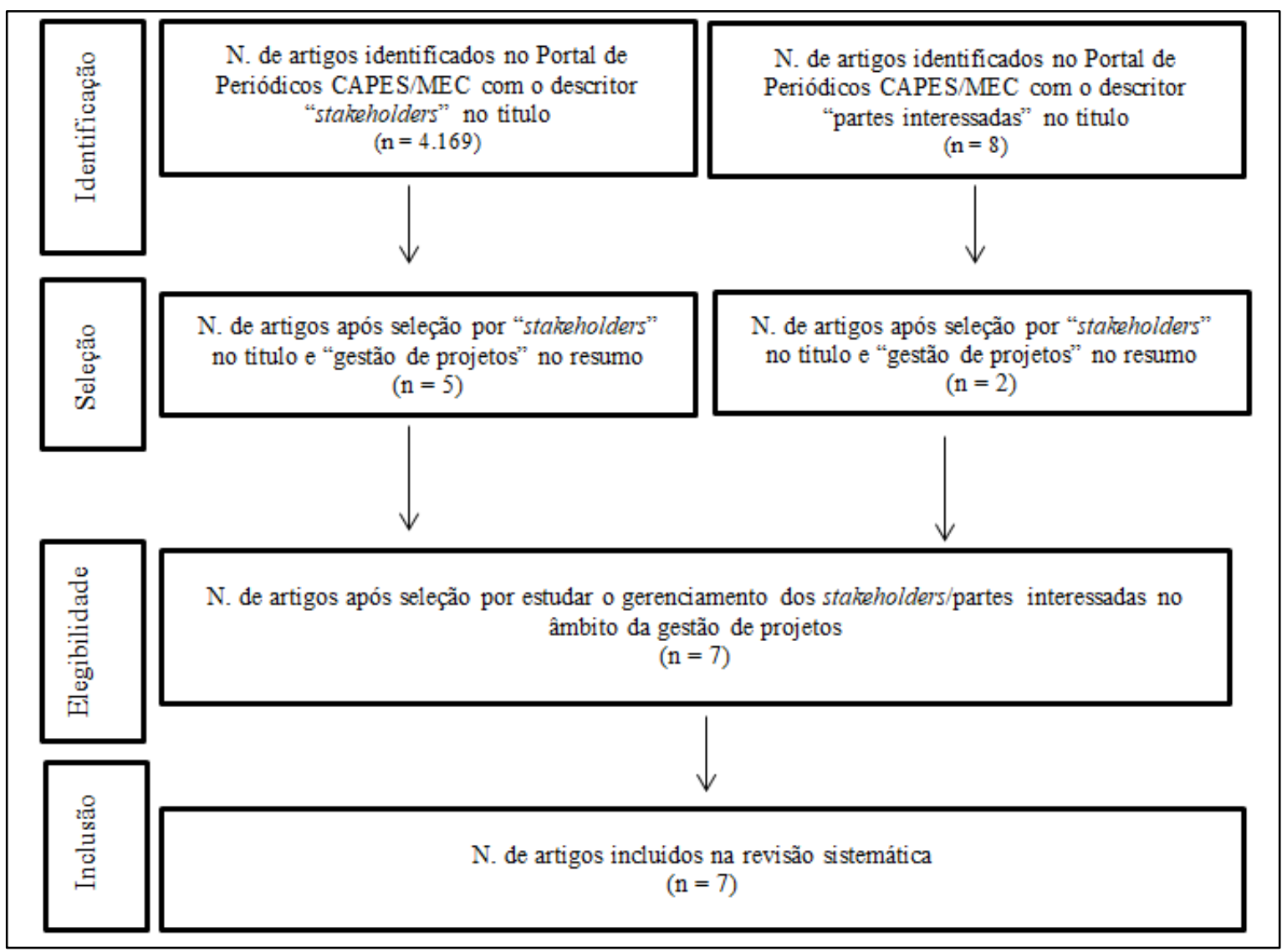

Fonte: Elaboração própria. Resultados da pesquisa, 2019. 
Concluídos os procedimentos do protocolo Prisma, os textos foram coletados em uma planilha no software Microsoft Excel com as seguintes informações: título, Qualis, volume, número e ano do periódico; autor e vinculação institucional; título, resumo e palavras-chave do texto; número de citações; objetivos; alicerce teórico; contexto de aplicação; enquadramento metodológico e principais conclusões. O Quadro 1 apresenta as principais características dos trabalhos selecionados, como os objetivos, a metodologia e os resultados.

Quadro 1: Principais características dos trabalhos selecionados

\begin{tabular}{|c|c|c|c|}
\hline Autores & Objetivo & Metodologia & Principais resultados \\
\hline $\begin{array}{l}\text { Duarte, } \\
\text { Biancolino e } \\
\text { Kniess (2013) }\end{array}$ & $\begin{array}{l}\text { Identificar se os gerentes de três } \\
\text { empresas de Tecnologia da } \\
\text { Informação fazem uma gestão } \\
\text { diferenciada para cada categoria } \\
\text { de stakeholder. }\end{array}$ & $\begin{array}{l}\text { Estudo de } \\
\text { caso }\end{array}$ & $\begin{array}{l}\text { Existe carência de processos e } \\
\text { indicadores que identifique } \\
\text { claramente as categorias de } \\
\text { stakeholders, embora os gerentes } \\
\text { façam uma gestão diferenciada para } \\
\text { os stakeholders. }\end{array}$ \\
\hline $\begin{array}{l}\text { Lopes e Mañas } \\
\text { (2013) }\end{array}$ & $\begin{array}{l}\text { Compreender o fenômeno dos } \\
\text { atrasos em relação à eficácia na } \\
\text { gestão dos stakeholders de } \\
\text { projetos de Tecnologia da } \\
\text { Informação. }\end{array}$ & $\begin{array}{l}\text { Pesquisa } \\
\text { exploratória }\end{array}$ & $\begin{array}{l}\text { Foram relataram casos em que } \\
\text { problemas na gestão dos } \\
\text { stakeholders impactaram } \\
\text { negativamente, direta ou } \\
\text { indiretamente, os prazos finais de } \\
\text { projetos de Tl, como alteração tardia } \\
\text { dos requisitos/escopo do projeto e } \\
\text { falta de recursos humanos } \\
\text { disponíveis na data acordada. }\end{array}$ \\
\hline $\begin{array}{l}\text { Martins, Silva e } \\
\text { Santos (2014) }\end{array}$ & $\begin{array}{l}\text { Classificar os principais } \\
\text { stakeholders e as estratégias de } \\
\text { interação de dois hospitais sem } \\
\text { fins lucrativos. }\end{array}$ & $\begin{array}{l}\text { Estudo de } \\
\text { caso }\end{array}$ & $\begin{array}{l}\text { Os dois hospitais reconhecem que os } \\
\text { principais stakeholders são os } \\
\text { médicos, as empresas e a } \\
\text { comunidade, classificada como uma } \\
\text { percepção reducionista. Não foi } \\
\text { captada evidência de } \\
\text { instrumentalização da relação com } \\
\text { os stakeholders. }\end{array}$ \\
\hline $\begin{array}{l}\text { Borges e } \\
\text { Carvalho (2015) }\end{array}$ & $\begin{array}{l}\text { Compreender a influência das } \\
\text { variáveis tipologia de projeto e } \\
\text { tipo de stakeholder nos critérios } \\
\text { de sucesso em projetos. }\end{array}$ & $\begin{array}{l}\text { Pesquisa de } \\
\text { campo }\end{array}$ & $\begin{array}{l}\text { Os resultados apontam para uma } \\
\text { influência significativa do tipo de } \\
\text { projeto na importância dos critérios } \\
\text { de sucesso, no entanto o mesmo não } \\
\text { ocorreu para o tipo de stakeholders. }\end{array}$ \\
\hline $\begin{array}{l}\text { Dias, Jeunon e } \\
\text { Duarte (2016) }\end{array}$ & $\begin{array}{l}\text { Analisar como se dá a gestão de } \\
\text { expectativas das partes } \\
\text { interessadas em projetos na } \\
\text { percepção de especialistas da } \\
\text { área. }\end{array}$ & $\begin{array}{l}\text { Pesquisa de } \\
\text { campo }\end{array}$ & $\begin{array}{l}\text { A "qualidade" foi a principal } \\
\text { expectativa das partes interessadas e } \\
\text { o fator "econômico" como o mais } \\
\text { influente nas expectativas em } \\
\text { projetos. As partes interessadas } \\
\text { estão classificadas com maior nível } \\
\text { de preocupação nas expectativas e } \\
\text { com nível de engajamento como } \\
\text { "apoiadoras", por estarem cientes } \\
\text { dos objetivos e do trabalho do } \\
\text { projeto, dando apoio às mudanças } \\
\text { aprovadas. }\end{array}$ \\
\hline $\begin{array}{l}\text { Nesello e } \\
\text { Fachinelli }\end{array}$ & $\begin{array}{l}\text { Discutir a integração de } \\
\text { diferentes abordagens de }\end{array}$ & Ensaio teórico & $\begin{array}{l}\text { As proposições para o } \\
\text { gerenciamento das partes }\end{array}$ \\
\hline
\end{tabular}




\begin{tabular}{|c|c|c|c|}
\hline (2017) & $\begin{array}{l}\text { gerenciamento de projetos para } \\
\text { uma melhor gestão das partes } \\
\text { interessadas em projetos de } \\
\text { inovação aberta. }\end{array}$ & & $\begin{array}{l}\text { interessadas em projetos de } \\
\text { inovação aberta foram apresentadas } \\
\text { na forma de um modelo teórico } \\
\text { conceitual, que teve como plano de } \\
\text { fundo o ciclo de vida adaptativo das } \\
\text { abordagens ágeis, integrando os } \\
\text { processos padrão do gerenciamento } \\
\text { das partes interessadas com o } \\
\text { refinamento necessário para } \\
\text { aplicação em projetos de inovação } \\
\text { aberta. }\end{array}$ \\
\hline $\begin{array}{l}\text { Amaral, Bastos } \\
\text { e Carvalho } \\
\text { (2018) }\end{array}$ & $\begin{array}{l}\text { Examinar como os gestores } \\
\text { identificam, classificam e } \\
\text { priorizam os stakeholders de um } \\
\text { evento esportivo (Volta da } \\
\text { USP/52a edição). }\end{array}$ & $\begin{array}{l}\text { Estudo de } \\
\text { caso }\end{array}$ & $\begin{array}{l}\text { Foi identificada diferença na } \\
\text { identificação dos stakeholders } \\
\text { dependendo do nível organizacional } \\
\text { a que o gestor pertence. O atributo } \\
\text { mais frequente foi o de legitimidade. } \\
\text { Quanto às tipologias os stakeholders } \\
\text { foram definidos com caráter } \\
\text { definitivo, dependente, dominante, } \\
\text { discricionário e inativo. A priorização } \\
\text { dos stakeholders pelos gestores } \\
\text { ocorre de forma a dar um nível de } \\
\text { importância maior para aqueles que } \\
\text { apresentam dois ou mais atributos } \\
\text { em detrimento daqueles que } \\
\text { apresentam apenas um dos } \\
\text { atributos. }\end{array}$ \\
\hline
\end{tabular}

Fonte: Elaboração própria. Resultados da pesquisa (2019).

Em relação aos artigos apresentados no Quadro 1, a maioria dos estudos se configuram como estudos de casos, que aplicam como análise do gerenciamento de projetos de organizações brasileiras, apresentando o papel desempenhado pelos stakeholders nesta perspectiva. Foi possível observar também que não há um padrão de autores mais citados, porém, há predominância da citação da obra seminal de Freeman (1984) a respeito do papel dos stakeholders para a gestão estratégica das organizações.

A autora Marly Monteiro de Carvalho é autora de dois artigos, nos quais um está mais relacionado à tipologia dos stakeholders (BORGES; CARVALHO, 2015) e o outro à identificação, classificação e à priorização de stakeholders de um evento esportivo (AMARAL; BASTOS, CARVALHO, 2018). Duas pesquisas têm como foco o gerenciamento dos stakeholders em projetos de Tecnologia da Informação (TI) (DUARTE; BIANCOLINO, KNIESS, 2013; LOPES; MAÑAS, 2013).

Lopes e Mañas (2013) destacam que problemas na gestão dos stakeholders impactam negativamente, direta ou indiretamente, os prazos finais de projetos de TI, como alteração tardia dos requisitos/escopo do projeto e falta de recursos humanos disponíveis na data acordada. Esta constatação corrobora com a perspectiva do PMI (2013), de que a má 
identificação ou falta de gerenciamento das expectativas dos stakeholders pode implicar em atrasos, aumento dos custos e outras consequências negativas, incluindo, até mesmo o cancelamento do projeto.

Considerando os quatro processos integrantes da área do conhecimento "partes interessadas", o PMBOK (PMI, 2013): i) identificação, ii) planejamento do gerenciamento, iii) gerenciamento do engajamento e iv) controle do engajamento, o Quadro 2 mostra as principais características destas etapas e o Quadro 3 mostra aspectos nos quais as pesquisas acadêmicas analisadas incorporam tais processos do gerenciamento dos stakeholders de projetos.

Quadro 2: Características dos processos de gerenciamento dos stakeholders de projetos

\begin{tabular}{|l|l|}
\hline Processos do PMBOK & Características dos processos \\
\hline $\begin{array}{l}\text { 1. Identificação das } \\
\text { partes interessadas }\end{array}$ & $\begin{array}{l}\text { Trata-se de identificar as pessoas, grupos ou organizações que podem impactar ou } \\
\text { ser impactos pelo projeto (seja por uma decisão, atividade ou resultado). Nesta } \\
\text { etapa são analisadas e documentadas as informações relevantes quanto aos } \\
\text { interesses, nível de engajamento, interdependências, influência e seu impacto no } \\
\text { bom andamento do projeto. }\end{array}$ \\
\hline $\begin{array}{l}\text { 2. Planejamento do } \\
\text { gerenciamento das } \\
\text { partes interessadas }\end{array}$ & $\begin{array}{l}\text { Desenvolvimento de estratégias adequadas para engajar cada uma das partes } \\
\text { interessadas de maneira eficaz ao longo de todo ciclo de vida do projeto, baseando- } \\
\text { se nas suas informações levantadas na primeira etapa. }\end{array}$ \\
\hline $\begin{array}{l}\text { 3. Gerenciamento do } \\
\text { engajamento das } \\
\text { partes interessadas }\end{array}$ & $\begin{array}{l}\text { Envolve a comunicação com as partes interessadas para atender às suas } \\
\text { necessidades e expectativas, abordando as questões e incentivando o engajamento } \\
\text { apropriado ao longo do ciclo de vida do projeto. }\end{array}$ \\
\hline $\begin{array}{l}\text { 4. Controle do } \\
\text { engajamento das } \\
\text { partes interessadas }\end{array}$ & $\begin{array}{l}\text { Inclui o monitoramento dos relacionamentos das partes interessadas do projeto e } \\
\text { os ajustes das estratégias e de planos para o engajamento das partes interessadas. }\end{array}$ \\
\hline
\end{tabular}

Fonte: Elaborado com base em PMI (2013).

Quadro 3: Como os trabalhos abordam o gerenciamento dos stakeholders conforme os processos do PMBOK

\begin{tabular}{|l|l|}
\hline Processos do PMBOK & Elementos dos processos do PMBOK identificados nos trabalhos \\
\hline \multirow{5}{*}{$\begin{array}{l}\text { Identificação das } \\
\text { partes interessadas } \\
\text { final do projeto (LOPES; MAÑAS, 2013). } \\
\text { As três empresas de TI participantes do estudo não conseguiram identificar } \\
\text { categorias distintas de stakeholders, mas criaram formas de gestão diferenciadas } \\
\text { para cada uma delas (DUARTE; BIANCOLINO, KNIESS, 2013). } \\
\text { Apenas médicos, empresas e a comunidade foram identificados como stakeholders } \\
\text { principais em dois hospitais religiosos, pois a gestão dos stakeholders é pouco } \\
\text { estruturada (MARTINS; SILVA, SANTOS, 2014). } \\
\text { Foram identificados stakeholders internos ao projeto, no entanto, a não } \\
\text { identificação de stakeholders externos prejudicou uma análise mais ampla da } \\
\text { interferência destes nos critérios de sucesso de projetos (BORGES; CARVALHO, } \\
\text { 2015). } \\
\text { Clientes, patrocinadores, gerentes do projeto e equipe do projeto foram os } \\
\text { stakeholders identificados (DIAS; JEUNON, DUARTE, 2016). } \\
\text { Nesello e Fachinelli (2017) destacam que, a identificação de partes interessadas, no } \\
\text { contexto da inovação aberta, deve ocorrer de forma alinhada às necessidades de } \\
\text { competências relacionadas ao projeto a ser desenvolvido. Ou seja, não se trata }\end{array}$} \\
\hline
\end{tabular}




\begin{tabular}{|c|c|}
\hline & $\begin{array}{l}\text { mais de apenas identificar as partes interessadas do projeto, mas sim de identificar } \\
\text { as partes externas necessárias para o seu desenvolvimento. Logo, este processo } \\
\text { requer um melhor entendimento do projeto a ser desenvolvido e, também, das } \\
\text { competências necessárias para tal. } \\
\text { Identificação de três diferentes tipos de stakeholders: gestores do projeto, } \\
\text { assistentes de coordenação e operações do projeto (AMARAL; BASTOS, CARVALHO, } \\
\text { 2018). }\end{array}$ \\
\hline $\begin{array}{l}\text { Planejamento do } \\
\text { gerenciamento das } \\
\text { partes interessadas }\end{array}$ & $\begin{array}{l}\text { A alteração de um ou mais stakeholders após o início do projeto pode afetar } \\
\text { negativamente seu prazo final (LOPES; MAÑAS, 2013). } \\
\text { Embora as empresas participantes da pesquisa tenham políticas distintas para } \\
\text { gerenciar as categorias de stakeholders envolvidos nos projetos, que existe uma } \\
\text { tendência inerente aos gerentes de projetos em aprimorar o processo de gestão do } \\
\text { poder de influência dos stakeholders, a fim de garantir o sucesso nos projetos de TI } \\
\text { (DUARTE; BIANCOLINO, KNIESS, 2013). } \\
\text { Conforme Nesello e Fachinelli (2017), este processo consiste em identificar as } \\
\text { competências essenciais para o desenvolvimento do projeto; localizar os } \\
\text { stakeholders entre as redes de colaboração/ inovação que a empresa está } \\
\text { envolvida e identificar a estratégia que a empresa irá adotar para engajar os } \\
\text { stakeholders no projeto. } \\
\text { Foi realizada uma priorização dos stakeholders por meio da classificação de } \\
\text { prioridade dos stakeholders segundo a percepção dos diferentes integrantes da } \\
\text { comissão organizadora de um evento esportivo (AMARAL; BASTOS, CARVALHO, } \\
\text { 2018). }\end{array}$ \\
\hline $\begin{array}{l}\text { Gerenciamento do } \\
\text { engajamento das } \\
\text { partes interessadas }\end{array}$ & $\begin{array}{l}\text { A má comunicação com um ou mais stakeholders pode afetar negativamente o } \\
\text { prazo final do projeto (LOPES; MAÑAS, 2013). } \\
\text { Duarte, Biancolino e Kniess (2013) destacam que a clara atribuição de } \\
\text { responsabilidades no projeto e a influência do gerente de projetos no sucesso e/ou } \\
\text { fracasso do projeto representam construtos relevantes devido à convergência } \\
\text { notada nas três empresas participantes do estudo. } \\
\text { O nível de engajamento dos stakeholders foi analisado conforme às seguintes } \\
\text { expectativas: financeira, qualidade, prazo, escopo, estratégica/negócio (DIAS; } \\
\text { JEUNON, DUARTE, 2016). } \\
\text { Para Nesello e Fachinelli (2017), no contexto da inovação aberta, o gerenciamento } \\
\text { das partes interessadas sai de uma posição de apenas identificar e gerenciar as } \\
\text { partes impactantes ou impactadas pelo projeto. Esta área de conhecimento passa a } \\
\text { orientar como gerentes de projetos e suas equipes podem buscar agentes externos } \\
\text { com as competências necessárias para o desenvolvimento do projeto. Isso pode ser } \\
\text { realizado sem perder as características do gerenciamento ágil de projetos. } \\
\text { Em relação aos stakeholders e à organização do evento esportivo, foi possível } \\
\text { observar um alinhamento entre os objetivos dos organizadores com os objetivos } \\
\text { dos stakeholders participantes em se envolverem com a prova (AMARAL; BASTOS, } \\
\text { CARVALHO, 2018). }\end{array}$ \\
\hline $\begin{array}{l}\text { Controle do } \\
\text { engajamento das } \\
\text { partes interessadas }\end{array}$ & $\begin{array}{l}\text { Lopes e Mañas (2013) destacam que é fundamental que os gerentes de projetos de } \\
\text { TI elaborem um plano formal para gerenciar os stakeholders do projeto, } \\
\text { considerando neste plano, dentre outros aspectos, como monitorar os principais } \\
\text { stakeholders com o intuito de prever comportamentos que possam impactar o } \\
\text { projeto. } \\
\text { No modelo conceitual desenvolvido por Nesello e Fachinelli (2017), abordando o } \\
\text { gerenciamento dos stakeholders e inovação aberta, as fases de execução e } \\
\text { monitoramento e controle permanecem da mesma forma como proposto no } \\
\text { PMBOK (PMI, 2013), com os processos de: “Gerenciar o engajamento das partes }\end{array}$ \\
\hline
\end{tabular}


Fonte: Elaboração própria. Resultados da pesquisa, 2019.

Lopes e Mañas (2013) enfatizam algumas constatações relevantes no que concerne ao gerenciamento dos stakeholders em projetos de TI. A primeira delas é que, se um stakeholder não for identificado logo no início do projeto tem chances de pedir algo novo quando for engajado; um segundo elemento é que um novo stakeholder (que substituiu outro), que tem a gestão de suas expectativas negligenciada, apresenta maiores chances de pedir mudanças nas entrega do projeto; outra constatação é que as fases de identificação de requisitos e de definição de escopo envolvem intensa comunicação com os stakeholders. Portanto, uma comunicação ineficiente nessas fases pode acarretar falhas na identificação dos requisitos do projeto, o que, por sua vez, pode gerar pedidos tardios de novos requerimentos e, consequentemente, prejudicar a entrega pontual do projeto.

Duarte, Biancolino e Kniess (2013) revelam que, embora as três empresas de TI participantes da pesquisa tenham políticas distintas para gerenciar as categorias de stakeholders envolvidos nos projetos, existe uma tendência inerente aos gerentes de projetos em aprimorar o processo de gestão do poder de influência dos stakeholders, a fim de garantir o sucesso nos projetos de TI. Sendo assim, os autores destacam que, o fator causador disto diz respeito à carência de processos, e indicadores, que identifiquem claramente as categorias de stakeholders. Existe uma reatividade, entre as empresas pesquisadas, de compor as categorias dos stakeholders, pois as políticas de gestão já foram criadas em tais empresas, mas resta finalizar o trabalho principal, por onde deveria ter sido iniciado o processo de gestão do poder de influência stakeholders, que diz respeito à identificação e a criação de cada uma das categorias.

No estudo de Martins, Silva e Santos (2014), em ambos os hospitais religiosos analisados, existe uma estratégia de atuação e gestão implícita dos stakeholders, suportada em uma identificação implícita e espontânea dos stakeholders, ou seja, a relação com os stakeholders é intrínseca ao próprio negócio e missão da organização, não sendo captada evidência de instrumentalização dessa relação.

Borges e Carvalho (2015) analisaram critérios de sucesso em projetos considerando a interferência dos stakeholders e constataram que, os critérios que aparecem com maior importância são: cumprimento de cronograma (prazo), cumprimento de requisitos, qualidade do serviço, cumprimento de prazo e clareza na comunicação. Já os critérios de menor destaque foram: parcela de mercado, tecnologia nova, nova competência essencial, capacidade dos fornecedores e nova capacidade organizacional.

Dias, Jeunon e Duarte (2016) destacam facilidades e dificuldades na gestão dos stakeholders e concluem, entre as principais facilidades destacam-se como mais marcantes a 
quebra de resistências na solução de problemas para aumentar o suporte ao projeto, a padronização das informações para todo o time de projeto e comunicação sobre o status atual e as necessidades reais do projeto. Das principais dificuldades, ressaltam-se a gestão dos conflitos gerados pelos interesses particulares de cada grupo de stakeholders relevantes, o mapeamento completo dos stakeholders considerando-se todas as interfaces de impacto na gestão, aprovações, levantamento dos requisitos e gestão dos riscos, o alinhamento das expectativas e a sincronização da gestão das demandas de cada equipe envolvida no projeto.

Nesello e Fachinelli (2017) desenvolveram um modelo conceitual abordando o gerenciamento dos stakeholders e inovação aberta. Os autores abordam que, primeiramente, o projeto deve ser enquadrado em projeto baseado na expertise, ideação ou tentativa e erro. Projetos de ideação ou tentativa e erro irão envolver um maior número de partes interessadas, cujas competências devem ser identificadas e localizadas nas redes de colaboração/inovação da empresa. Além disso, o engajamento destas partes interessadas no projeto é algo que terá que ser desenvolvido. Todos estes processos fazem parte o planejamento. Posteriormente, o engajamento destas partes deverá ser gerenciado e controlado. Com isso, a expectativa é que se tenha um melhor desempenho do projeto por meio das partes que o compõe.

Amaral, Bastos e Carvalho (2018) utilizaram tipologias para classificar os stakeholders, sendo stakeholders com caráter definitivo, dependente, dominante, discricionário e inativo. Os autores enfatizam no trabalho que, os stakeholders possuidores de três atributos (poder, legitimidade e urgência) são abordados pela literatura como "stakeholders definitivos", os que possuem dois atributos são os "stakeholders expectantes", (dominante - poder e legitimidade, dependente - legitimidade e urgência e perigoso - poder e urgência), os que possuem apenas um dos atributos são considerados "stakeholders latentes" (demandante - urgência, discricionário - legitimidade e inativo - poder).

\section{CONSIDERAÇÕES FINAIS}

O presente artigo cumpre com o objetivo proposto de realizar uma revisão sistemática da literatura a respeito dos estudos de gerenciamento de stakeholders no âmbito dos artigos indexados no repositório do Portal de Periódicos da Capes. Os resultados revelam as principais características dos trabalhos selecionados e, como estes elementos podem ser associados aos quatro processos integrantes da área do conhecimento "partes interessadas" do PMBOK (PMI, 2013): i) identificação, ii) planejamento do gerenciamento, iii) gerenciamento do engajamento e iv) controle do engajamento dos stakeholders.

Considerando os sete artigos selecionados, foi possível verificar que, Lopes e Mañas (2013) e Duarte, Biancolino e Kniess (2013) analisaram o gerenciamento de stakeholders de projetos de TI. Martins, Silva e Santos (2014) não captaram evidência de instrumentalização da 
relação entre os stakeholders com os dois hospitais religiosos. Borges e Carvalho (2015) analisaram critérios de sucesso em projetos considerando a interferência dos stakeholders. Dias, Jeunon e Duarte (2016) destacam facilidades e dificuldades na gestão dos stakeholders na percepção de especialistas da área. Já Nesello e Fachinelli (2017) e Amaral, Bastos e Carvalho (2018) focaram no desenvolvimento de um modelo conceitual abordando o gerenciamento dos stakeholders e na utilização de tipologias para classificar os stakeholders, respectivamente.

Vale ressaltar a relevância desta pesquisa, considerando a importância dos stakeholders no âmbito da gestão de projetos e a contribuição teórica para o avanço da análise do estado da arte desta temática. A limitação das buscas no repositório do Portal de Periódicos da Capes pode ser considerada como limitação do trabalho, o que deixa espaço para sugestão de pesquisas futuras, considerando outros repositórios para a realização de revisões sistemáticas referentes à temática do gerenciamento dos stakeholders na gestão de projetos.

\section{REFERÊNCIAS}

AMARAL, C. M. S.; BASTOS, F. C.; CARVALHO, M. M. Mapeamento de stakeholders em projetos de eventos esportivos: estudo de caso. PODIUM Sport, Leisure and Tourism Review, v. 7, n.1, p. 22-45, 2018.

BORGES, J. G.; CARVALHO, M. M. Critérios de sucesso em projetos: um estudo exploratório considerando a interferência das variáveis tipologia de projetos e stakeholders. Production, v. 25, n. 1, p. 232-253, 2015.

DIAS, A. M. M.; JEUNON, E. E.; DUARTE, L. C. Gestão das expectativas das partes interessadas: um estudo da percepção dos profissionais em gestão de projetos. Revista Inovação, Projetos e Tecnologia, v. 4, n. 2, p. 208-22, 2016.

DUARTE, C. C. M; BIANCOLINO, C. A.; KNIESS, C. T. Análise da gestão de Stakeholders aplicada ao gerenciamento de projetos de tecnologia da informação. Revista Eletrônica de Ciência Administrativa, v. 12, n. 3, p. 264-272, 2013.

FRANCO, E. F.; SÓ, B.; ROCHA, A. M.; SANTOS; F. N.; CARVALHO, M. M. Gestão de Stakeholders em Gestão de Projetos: Levantamento Bibliométrico. Produto \& Produção, v. 17, n. 3, p. 32-45, 2016.

FREEMAN, R. E. Strategic Management: A Stakeholder Approach. Boston, MA: Pitman, 1984.

FREEMAN, R. E.; HARRISON, J. S.; WICKS, A C. Managing for stakeholders: Survival, reputation, and success. Yale University Press, 2007.

GAO, S. S.; ZHANG, J. J.. Stakeholder engagement, social auditing and corporate sustainability. Business Process Management Journal, v. 32, p.722-740, 2006.

GOMES, R. C; GOMES, L. O. M. Proposing a theoretical framework to investigate the 
relationships between an organization and its environment. Revista de Administração Contemporânea, v. 11, n. 1, p. 75-96, 2007.

GUPTA, A. A stakeholder analysis approach for inter-organizational systems. Industrial Management \& Data Systems, v. 95, n. 6, p. 3-7, 1995.

LOPES, L.; MANÃS, A. V. Atrasos em projetos de TI causados por falhas na gestão dos stakeholders. Future Studies Research Journal, v.5, n.2, p. 155-186, 2013.

MARTINS, F. A.; SILVA, A. F.; SANTOS, C. M. Gestão dos Stakeholders na Captação de Recursos nos Hospitais Filantrópicos e Religiosos. Revista de Administração Contemporânea, v. 18, p. 65-85, 2014.

MUSHOVE, P., VOGEL, C.. Heads or tails? Stakeholder analysis as a tool for conservation area management. Global Environmental Change, v. 15, n. 3, p. 184-198, 2005.

MOHER, D. et al. Preferred Reporting Items for Systematic Reviews and Meta-Analyses: The PRISMA Statement. Systematic Reviews, v. 4, n. 1, p. 1-9, 2015.

NESELLO, P.; FACHINELLI, A. C. Gestão das partes interessadas e inovação aberta: um ensaio teórico na perspectiva do gerenciamento de projetos. Revista Gestão e Projetos, v. 8, n. 3, p. $50-65,2017$.

PROJECT MANAGEMENT INSTITUTE (PMI). PMBOK GUIA. Um guia do conhecimento em gerenciamento de projetos. 5. ed. EUA, 2013.

SCHMEER, K., Guidelines for Conducting a Stakeholder Analysis. Partnerships for Health Reform, Abt Associates Inc., Bethesda, MD, 1999.

WEIBLE, C. M. An advocacy coalition framework approach to stakeholder analysis: Understanding the political context of California marine protected area policy. Journal of public administration research and theory, v. 17, n. 1, p. 95-117, 2006. 